\title{
Huge Teardrop Fracture of the Axis: Literature Review and Case Report
}

\section{Juan Pablo Santelices ${ }^{1}$, Rodrigo Donoso ${ }^{2 *}$, Daniel Palma ${ }^{3}$, Marcos Ganga $^{1,4}$ and Cristián Santos ${ }^{1,5}$}

${ }^{1}$ Spine Surgeon, Equipo de Cirugía de Columna, Clínica Santa María, Santiago, Chile

${ }^{2}$ Orthopedic Surgeon, Spine surgery fellow, Universidad de Chile, Chile

${ }^{3}$ Orthopedic Surgery Resident, Universidad de Chile, Chile

${ }^{4}$ Associate Professor, Universidad de Chile, Orthopedic Surgery Program, Spine

Surgery Division, Chile

${ }^{5}$ Spine Surgeon, Spine Surgery Chief, Equipo de Cirugía de Columna, Clínica Santa

María, Santiago, Chile

*Corresponding Author: Rodrigo Donoso, Orthopedic Surgeon, Spine surgery fellow, Universidad de Chile, Chile.
Received: September 20, 2021

Published: November 10, 2021

(C) All rights are reserved by Rodrigo

Donoso., et al.

\begin{abstract}
Huge teardrop fracture of the axis is an uncommon injury, mainly caused by high energy trauma. Despite of being described for the first time in 1956, the evidence is still scarce.

Purpose: To review the literature, analyze and discuss the treatment options and its results for this type of fracture. We present a clinical case of huge teardrop fracture of the axis.

Methods: Literature review between 1956 and 2020, discussion of the treatment options and results. Description of the treatment method and results in our mentioned clinical case.

Results: We present a patient with a huge teardrop fracture of the axis due to high energy trauma (parachute diving accident by malfunction of main device). Treatment decision is discussed considering the eventual benefits and risks, finally performing a C2-C3 anterior fusion augmented with iliac crest autograft. There are 79 cases described in the literature, but the cases solved by surgery are not more than 20 .
\end{abstract}

Keywords: Huge Teardrop Axis Fracture; Teardrop Fracture, Axis Fracture; Cervical Fusion; Anterior Approach; Cervical Arthrodesis

\section{Introduction}

Huge teardrop fractures of the axis are extremely infrequent injuries, being initially described by Kahn and Schneider [1] in 1956. This is the main reason why there are scarce literature reports, being the retrospective review of Hu., et al. in 2013 the most representative with 16 cases [2].
These fractures have been described in high energy trauma settings, the main mechanism is hyperextension and distraction of the cervical spine [3]. Despite the knowledge of the biomechanics of this fracture, there is no consensus regarding the treatment, being reported conservative and surgical management, using anterior, posterior or combined approaches [4]. 
The objectives of this article are:

- $\quad$ To expose a successful clinical case solved by surgical treatment with anterior submandibular approach, direct reduction, C2-C3 discectomy and fusion using tricortical iliac crest autograft.

- Perform a literature review to know the current state of the art.

\section{Materials and Methods}

Case report and literature review. Ethics committee approval of our institution and patient informed consent are obtained with their respective written record.

The literature review was performed searching the key words "teardrop", "axis", "fracture" using MEDLINE (PubMed), Embase, Cochrane and LILACS searching databases, also Google Scholar search was done. No coincidences were found in the Cochrane database. Using the MEDLINE database we found 10 references in English language. Two different articles were found at Google Scholar, one in French language and the other one in English. Using LILACS (Spanish language) with key words in Spanish did not yield any coincidences. The literature review is summarized in table 1.

\section{Clinical case}

The patient was a 36 year old male, without medical record of chronic diseases. While performing parachute diving he suffered a malfunction of his main parachute device, needing to use the emergency parachute, consequently he presented a whiplash mechanism of trauma while being in the air. His neurological exam was normal, classified as ASIA E.

He first attended an emergency department of a trauma center, being managed with a rigid cervical orthosis (Miami cervical orthosis) and referred to our institution because of his health insurance, being evaluated at the emergency department, obtaining cervical spine CT scan (Figure 1 and 2), cervical spine MRI (Figure 3, 4 and 5) and admitted to surgical management after a spine surgeon consultation.

At the admission he had a VAS scale (neck) of 7 if some motion was performed, and 0 if he kept the cervical orthosis. His Neck Disability Index (NDI) score was $62 \%$ (scale $0 \%$ to $100 \%$ ) when he was admitted [5].

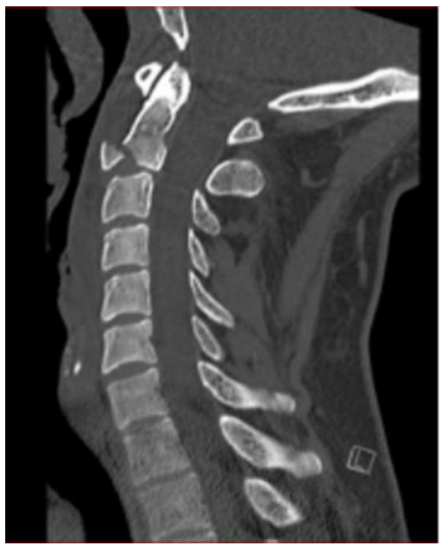

Figure 1: Admission CT scan, sagittal plane.

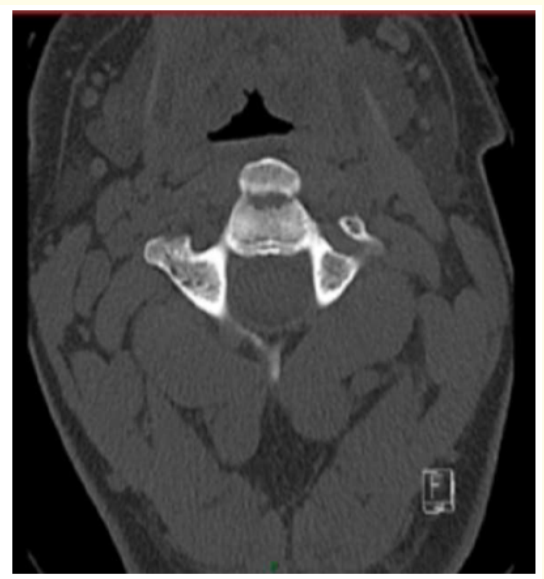

Figure 2: Admission CT scan, axial plane.

\section{Surgical technique}

Patient under general anesthesia, orogastric tube, with neuromonitoring assistance. Supine position with traction to both arms. Identification of C2-C3 level under C-arm vision. Preoperative preparation of skin and sterile draping.

Regarding the operative technique, we used a modified SmithRobinson approach, we managed to access C2-C3 level through a submandibular paramedian transverse incision done by the left side (Figure 6), an oblique access through the platysma muscle, underlying plane of sternocleidomastoid and omohyoid muscles, 
blunt dissection identifying carotid sheath to lateral and esophagus to medial, protecting them with blunt spreaders. Dissection of prevertebral fascia and longus colli muscles.

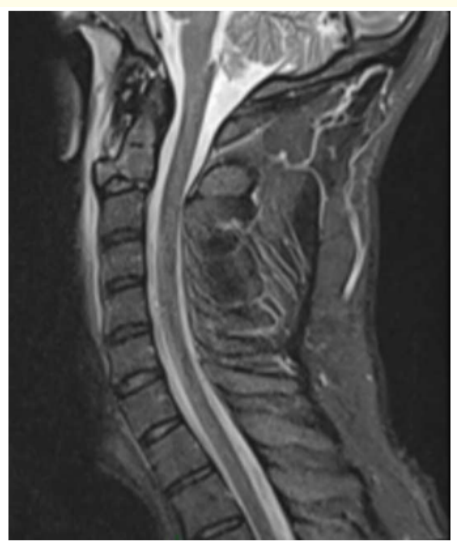

Figure 3: Cervical spine MRI - T2 weighted sagittal.

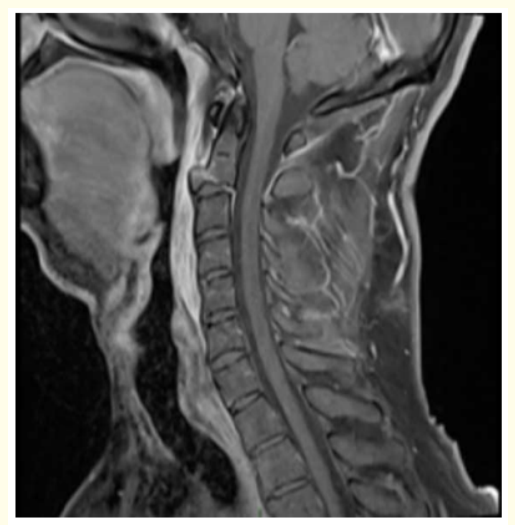

Figure 4: Cervical spine MRI - T1 weighted sagittal.

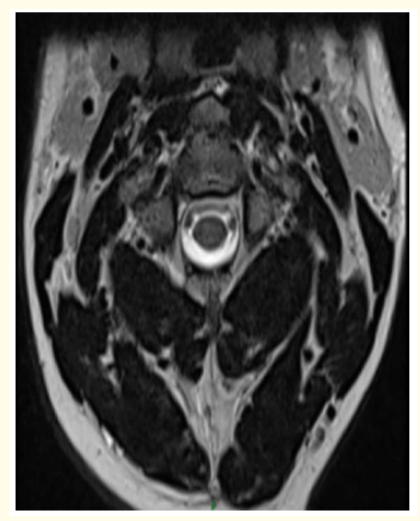

Figure 5: Cervical spine MRI - T2 weighted axial image.
Some differences related to the classic Smith-Robinson approach to lower cervical levels have to be mentioned. Literature reports describe that the submandibular gland appears attached to the digastric muscle, superior laryngeal nerves and vessels can be identified and superior thyroid, superior laryngeal and lingual arteries are important to preserve to avoid important bleeding $[6,7]$. Even though these structures are mentioned as anatomic landmarks when performing this approach, we were not able to see them at this surgery.

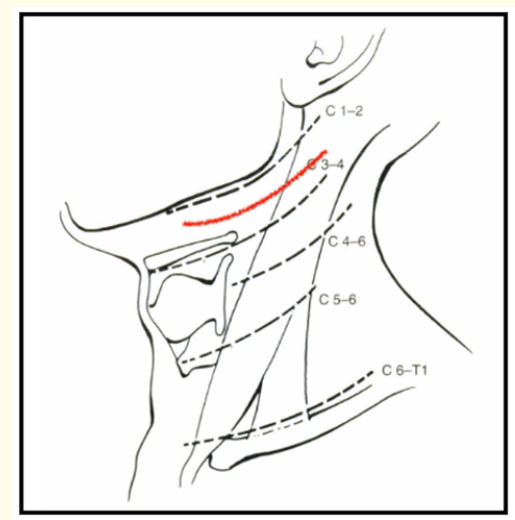

Figure 6: Referential image of submandibular Smith-Robinson approach.

Disc space C2-C3 verification under C-arm vision and discectomy, C2 body anteroinferior fragment resection, vertebral plates chondral resection with curettes. Left iliac crest tricortical graft is obtained, which is modeled and placed into the intervertebral space, reinserting anteroinferior C2 bone fragment previously excised (Figure 7).

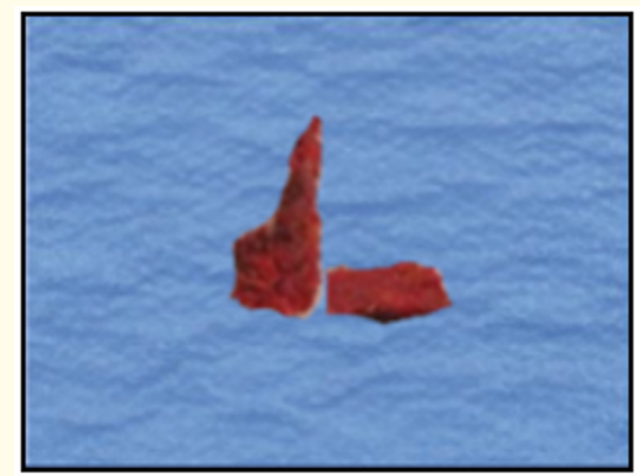

Figure 7: Modeled tricortical iliac crest graft. 
Anterior fixation with $20 \mathrm{~mm}$ Vectra ${ }^{\circledR}$ cervical plate (DePuy Synthes), two $16 \mathrm{~mm}$ length screws to $\mathrm{C} 2$ body and two $18 \mathrm{~mm}$ length screws to $\mathrm{C} 3$ body, verifying position under $\mathrm{C}$-arm assistance (Figure 8). 0 -arm ${ }^{\circledR}$ verification of adequate position of the plate and screws.
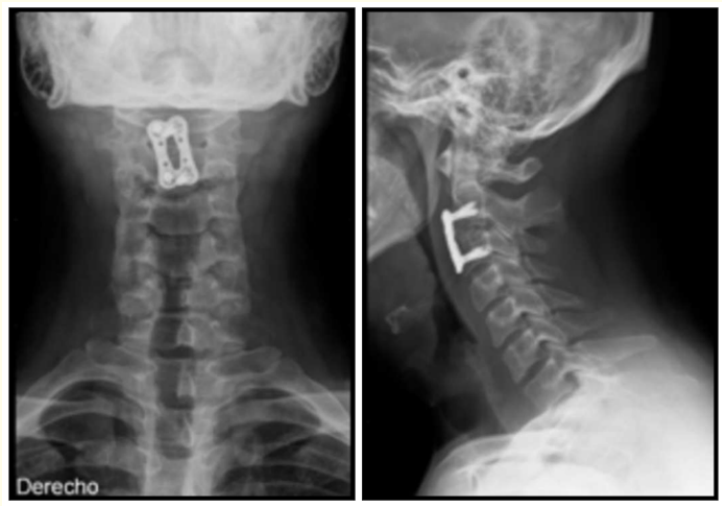

Figure 8: Immediate post surgical X-Rays.

Lavage with saline solution, hemostasis with monopolar and bipolar electrocautery. Platysma and subcutaneous suture with Vicryl 2-0 and intradermic skin suture with Ethilon 3-0.

\section{Follow up}

After the surgery, the patient kept without neurological deficits, he received physical therapy assistance the first day to perform walking and was kept protected with a rigid cervical orthosis, avoiding extreme range of motion movements. He was discharged on the second postoperative day.

The patient did not present wound complications and his neurological status remained normal. He was followed up with x-rays one, three and six month after surgery (Figure 9). The rigid orthosis was removed at the first month and was replaced for a flexible orthosis for the following month. There was no evidence of osteolysis, failure of implants or any other complication, keeping the same position (Figures 6 to 11). At the 6 month evaluation his VAS score (neck) was 0 and his NDI score was $4 \%$ [5].

\section{Literature Review}

We performed a review of 12 articles, as mentioned previously in the article. The studied articles are summarized in table 1.

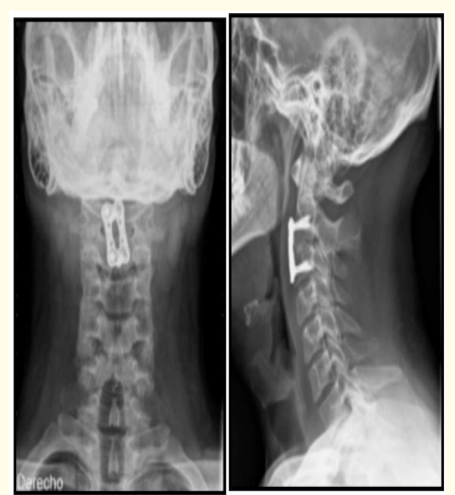

Figure 9: Six months follow up X-Rays.

Since the description of this fracture pattern in 1956 [1] until now, we found a total of 79 cases reported. Regarding the treatments applied, we highlight that the objective of bone healing is achieved with the conservative management and with surgeries, however the bone healing criteria is not defined in the previous publications. The total cases treated with surgery are not more than 20.

There are no publications in the literature comparing conservative versus surgical management, also there is just 1 report that evaluates functional outcomes of the patients [8].

Regarding the surgical techniques, there are described anterior and posterior approaches, existing a slight trend towards the first one the last decade [4,9-12]. This could be explained because of the availability of performing and adequate reduction of the fracture with a straight view of the affected bone and also because of the growing knowledge and experience of the surgeons using this approach.

The use of tricortical iliac crest autograft is a new trend seen in the last four publications [10-13]. Apparently the properties of the autograft have been reliable for the surgeons, considering that in this kind of surgeries increasing the healing potential and avoiding further surgeries are desirable objectives.

\section{Discussion and Conclusions}

Tear drop fracture of the axis is an infrequent clinical feature. Publications in the literature are scarce and are mainly case re- 
ports. The reviews reporting the most cases totalize 16 patients [2] and not all of them were solved by surgical means.

Results are excellent using conservative and surgical treatment if we consider the fracture healing as the main outcome. There are not reports comparing conservative and surgical treatment using functional scores as an outcome.

We did not find reports of the time of recovery related to both conservative and surgical treatment. However, the main advantage of surgery would be related to this matter.

Conservative management requires the use of rigid orthosis (collars) for 2 to 6 months [3,13,14], sometimes being uncomfortable for the patient. Also, the prolonged use of rigid orthosis has complications, for example, chin and back neck pressure ulcers $[15,16]$. The main advantage of the conservative treatment would be the avoidance of the surgical complications, however there are not reports published about this matter. Hence, it has to be considered as a valid option of treatment.
There are not absolute indications reported of surgical treatment based uniquely on the fracture. The surgical resolution is usually decided based on features like the fragment size, displacement or angulation of the fracture, intervertebral disk injury, neurologic deficit, soft tissue injuries (i.e. esophagus, trachea) and instability signs (for example posterior complex disruption) [2]. However, there is not consensus about this matter. In our case, we pondered some of those factors (size, displacement, angulation, disk injury). It was also weighed some of the patient conditions like age, functionality and his desire of a rapid return to work.

Hu., et al. proposed a method to measure displacement and angulation that seems to be good to reach consensus to further publications. However, the decision of surgery or orthopedic treatment was not based on this method. It has to be mentioned that there is not a correlative pattern between follow up results and displacement, angulation or size of the fracture fragment [2].

Currently, the trend of surgical treatment considers anterior approach, tricortical iliac crest autograft and specific cervical plate fixation as the main techniques implemented.

\begin{tabular}{|c|c|c|c|c|c|}
\hline Authors & Year & Journal & $\mathbf{N}$ & Treatment (approach) & Outcome \\
\hline Kahn., et al. & 1956 & J Bone Joint S & 14 & Distraction/surgery & Healed \\
\hline Korres., et al. & 1994 & Eur Spine J & 14 & Conservative & Healed \\
\hline Vialle., et al. & 2004 & $\begin{array}{c}\text { Rev Chir Orthop } \\
\text { Reparatrice Appar Mot }\end{array}$ & 1 & Posterior fixation & Healed \\
\hline Boran., et al. & 2005 & $\begin{array}{l}\text { Eur J Orthop Surg } \\
\text { Traumatol }\end{array}$ & 7 & Conservative & Healed \\
\hline Watanabe., et al. & 2011 & J Neurosurg Spine & 13 & Conservative & Healed \\
\hline Hu., et al. & 2013 & Clin Spine Surg & 16 & $\begin{array}{l}\text { Conservative/anterior and posterior } \\
\text { approaches }\end{array}$ & Healed \\
\hline Xu., et al. & 2014 & J Pediatr Orthop B & 1 & Traction/anterior approach & Healed \\
\hline Yang., et al. & 2015 & Spine & 1 & $\begin{array}{c}\text { Anterior approach (trapezoid bone } \\
\text { autograft) }\end{array}$ & Healed \\
\hline Ma., et al. & 2016 & Medicine & 1 & $\begin{array}{c}\text { Anterior approach (tricortical iliac crest } \\
\text { autograft) }\end{array}$ & Healed \\
\hline Govindan., et al. & 2016 & Int J Orthop & 1 & $\begin{array}{l}\text { Anterior approach (tricortical iliac crest } \\
\text { autograft) }\end{array}$ & Healed \\
\hline Jiang., et al. & 2017 & J Orthop Sci & 7 & $\begin{array}{c}\text { Anterior approach (tricortical iliac crest } \\
\text { autograft) }\end{array}$ & Healed \\
\hline Xin., et al. & 2019 & World Neurosurg & 3 & $\begin{array}{l}\text { Anterior approach, tricortical iliac crest } \\
\text { autograft, low profile plate and mini frag- } \\
\text { ment screws }\end{array}$ & Healed \\
\hline
\end{tabular}

Table 1: Literature review of teardrop fracture of the axis. 


\section{Bibliography}

1. Kahn E A and R C Schneider. "Chronic neurological sequelae of acute trauma to the spine and spinal cord. I. The significance of the acute-flexion or tear-drop fracture-dislocation of the cervical spine". The Journal of Bone and Joint Surgery. American Volume 38-A.5 (1956): 985-997.

2. Hu Yong., et al. "Conservative and Operative Treatment in Extension Teardrop Fractures of the Axis". Clinical Spine Surgery 29.1 (2016): E49-54.

3. Korres D S., et al. "The "tear drop" (or avulsed) fracture of the anterior inferior angle of the axis". European Spine Journal : Official Publication of the European Spine Society, the European Spinal Deformity Society, and the European Section of the Cervical Spine Research Society 3.3 (1994): 151-154.

4. Yang Xiaobin., et al. "Treating Huge Tear-Drop Fracture of Axis With Trapezoidal Bone: A Case Report and Literature Review". Spine 40.22 (2015): E1187-1190.

5. Kovacs Francisco M., et al. "Psychometric characteristics of the Spanish version of instruments to measure neck pain disability”. BMC Musculoskeletal Disorders 9 (2008): 42.

6. Park Soo-An., et al. "Topographical anatomy of the anterior cervical approach for c2-3 level”. European Spine Journal : Official Publication of the European Spine Society, the European Spinal Deformity Society, and the European Section of the Cervical Spine Research Society 22.7 (2013): 1497-1503.

7. Russo Antonino., et al. "Submandibular approach to the C2-3 disc level: microsurgical anatomy with clinical application". Journal of neurosurgery. Spine 10.4 (2009): 380-389.

8. Boran Sun., et al. "Functional outcome following teardrop fracture of the axis". European Journal of Orthopaedic Surgery and Traumatology 15.3 (2005): 229-232.

9. Xu Guanhua., et al. "Tear-drop fracture of the axis in a child with an 8-year follow-up: a case report". Journal of Pediatric Orthopedics. Part B 23.3 (2014): 299-305.

10. Ma Litai., et al. "Anterior Reduction, Discectomy, and Three Cortical Iliac Bone Grafting With Instrumentation to Treat A Huge Tear Drop Fracture of the Axis: A Case Report and Literature Review". Medicine 95.15 (2016): e3376.

11. Govindan Nijith O., et al. "Anterior Cervical Plating for An Axis Tear Drop Fracture: Case Report". International Journal of Orthopaedics 3.5 (2016): 650-653.
12. Jiang, Tao., et al. "Anterior reduction and fusion for treatment of massive tear drop fracture of axis combining with inferior endplate serious traversed lesion: A retrospective study". Journal of Orthopaedic Science : Official Journal of the Japanese Orthopaedic Association 22.5 (2017): 816-821.

13. Watanabe Masahiko., et al. "Clinical features of the extension teardrop fracture of the axis: review of 13 cases". Journal of Neurosurgery. Spine 14.6 (2011): 710-714.

14. Chan M., et al. "Cervical spine injuries and collar complications in severely injured paediatric trauma patients". Spinal Cord 51.5 (2013): 360-364.

15. Webber-Jones Joan E., et al. "The management and prevention of rigid cervical collar complications". Orthopedic Nursing 21.4 (2002): 19-25; quiz 25-27.

16. Vialle R., et al. "Fracture « tear-drop » en extension de l'axis: À propos d'un cas traité chirurgicalement". Revue de Chirurgie Orthopédique et Réparatrice de l'Appareil Moteur 90.2 (2004): 152-155.

17. Xin Xin., et al. "Zero-Profile Implantation Combined with Miniscrew Fixation via Anterior Approach for Huge Teardrop Fracture of Axis". World Neurosurgery 128 (2019): 235-239.

\section{Volume 4 Issue 12 December 2021 (C) All rights are reserved by Rodrigo Donoso., et al.}

